\title{
Single-Walled Nanotube
}

National Cancer Institute

\section{Source}

National Cancer Institute. Single-Walled Nanotube. NCI Thesaurus. Code C62392.

A carbon nanotube comprised of a single layer of graphitic carbon. These tubes may be metallic or semi-conducting depending on the chirality of the tube. 